\title{
Etnomarketing. La dimensión cultural del marketing
}

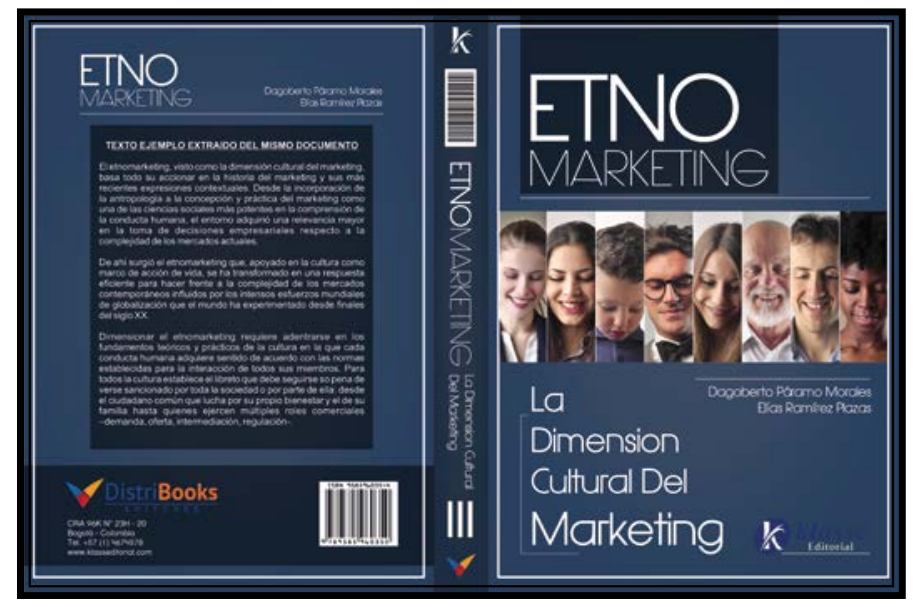

Elías Ramírez \& Dagoberto Páramo (2017). Etnomarketing. La dimensión cultural del marketing. Bogotá: Klasse editorial.

A la luz de las nuevas tendencias que se han venido imponiendo en el marketing, visto como un proceso social y cultural, ha surgido una corriente de pensamiento sustentada en el paradigma relativista. Así, la cultura ha comenzado a ser vista como el telón de fondo donde se desarrollan los comportamientos de los diferentes agentes de mercado y donde también ciertos productos han venido adquiriendo un simbolismo no imaginado antes (Lindridge and Dibb, 2003). Las organizaciones son vistas también como una cultura donde se tejen relaciones e interacciones en la vida cotidiana que las hacen únicas e irrepetibles. Como resultado, más allá de las consideraciones instrumentalistas, sociológicas, sociales, de intercambio de beneficio mutuo, estratégicas, administrativas, y de ingeniería, (Páramo, 2005) ha emergido con fuerza en las últimas décadas en el concierto mundial de académicos e investigadores, una tendencia a contemplar el marketing en el marco de una cultura determinada (Douglas and Isherwood, 1979; Arnould and Wallendorf, 1994; Páramo, 2000a, 2000b).

Esta nueva tendencia ha contrariado el paradigma dominante de considerar a un país como sinónimo de una misma cultura (Rao, 1997) y por tanto como un mercado homogéneo.
Existen suficientes evidencias que reafirman que las sociedades actuales están constituidas, en gran medida, por una gran diversidad de subculturas que corresponden a los diferentes grupos humanos existentes en el marco de un mismo territorio. Frente a esta realidad, el marketing ha sido testigo de un incesante crecimiento del interés por el estudio de las diferencias interculturales entre grupos étnicos y sus implicaciones para el marketing y ello lo ha obligado a recurrir a lo étnico y a lo cultural como criterio básico no solo de segmentación, sino como foco de atención comercial.

Más allá de algunos trabajos realizados en Australia dado su particular multiculturalismo (Pires, 1999), es muy poco lo que se ha hecho respecto al marketing concebido y desarrollado en un país con una notable diversidad cultural en su trasfondo histórico como sucede en buena parte de los países latinoamericanos donde converge lo indígena, lo africano y lo europeo, con diferentes matices y con disímiles mezclas (Triana, 1989). Contrario a lo que se acepta por doquier, tampoco la presencia de grandes empresas multinacionales que han ingresado a los países en vías de desarrollo con enormes recursos económicos y financieros, han logrado romper la tradición que se soporta estos 
innegables embates. La cultura, más bien, se ha convertido en una barrera que ha detenido estos intentos de homogenizar no únicamente el pensamiento de inmensas capas de la población, sino su aceptación de productos y marcas de gran prestigio internacional.

Por ello y ante la extrema necesidad que viven sobre todo las micro y pequeñas organizaciones mundiales de culturizar su proceso de concepción, implementación y control del marketing como filosofía empresarial y organizacional, ha emergido el etnomarketing, reafirmando el carácter contextual del marketing, donde la cultura -la del consumidor, la de la organización, la de los intermediarios, la de los agentes de la regulación- se asume como conductora y guía de la acción que cada rol impone. A diferencia de otras aproximaciones que se han quedado solo en la perspectiva cultural del consumo (Desjeux, 1990), en esta visión se considera también la organización como una cultura y en tanto que tal se convierte en instrumento vital para que la empresa alcance sus propósitos corporativos. Estos agentes del mercado -de la demanda, de la oferta-, por estar siendo conectados a través de la intermediación deben ser vistos desde los patrones culturales prevalecientes y estrechamente vigilados por el Estado y sus agencias gubernamentales.

El etnomarketing, entendido como la dimensión cultural del marketing, ha sido aplicado en diferentes segmentos de mercado, con distintos tipos de productos y sobre todo en empresas de diversos tamaños y con diferentes presupuestos para la conquista y conservación de mercados. La validez de sus planteamientos ha sido puesta a prueba en momentos y circunstancias de consumo y de competitividad diferentes, incluso antagónicos.

Dada la trascendencia del etnomarketing, este libro ha sido escrito en un lenguaje mucho más accesible del acostumbrado en el mundo académico. Su estructura ha sido concebida para que cualquier persona se acerque al etnomarketing y con una serie de reflexiones y sugerencias básicas pueda sacar provecho de esta revolucionaria propuesta.
La relevancia del etnomarketing no solo nace de la solidez de sus fundamentos teóricos presentados en foros académicos de talla mundial, sino que los resultados obtenidos por las empresas donde han sido aplicados son fieles testigos de su importancia tanto en la planeación como en la implementación de las múltiples estrategias de marketing que pueden ser aplicadas.

De esta manera, el libro ha sido dividido en cuatro partes y en catorce capítulos que tomados de forma secuencial dan una idea clara de la utilidad práctica y didáctica con la que ha sido concebida su estructura y su pragmática aproximación a la compleja realidad de los mercados contemporáneos:

En la primera parte denominada Fundamentos del etnomarketing, se presentan de forma sencilla las bases teóricas, epistemológicas y científicas que respaldan al etnomarketing. Consta de cuatro capítulos: Etnomarketing, Cultura y etnomarketing, Pilares teóricos del etnomarketing, Principios básicos del etnomarketing.

En la segunda parte titulada Antropología de mercados, una de las más novedosas, se presenta la aproximación cultural a los diferentes agentes del mercado. Consta de cuatro capítulos: Antropología de consumo, Antropología organizacional, Antropología de la intermediación, Antropología del sector regulador.

En la tercera parte denominada Matriz Estratégica del Etnomarketing, MEE, se formulan las quince actividades que, asociadas a las tres funciones del etnomarketing, deben ser desarrolladas para poner en práctica sus planteamientos. Está compuesta por tres capítulos: Comprender consumidores, Conquistar compradores, Conservar clientes.

En la cuarta parte titulada Implementación del etnomarketing en la empresa, se proporcionan los elementos prácticos para su operación. Consta de tres capítulos: Etnomarketing y etnografía, Etnomarketing y organización, Planeación y etnomarketing. 
Con la deliberada intención de presentar de forma sencilla y clara los planteamientos teóricos y prácticos del etnomarketing, este libro ha sido diseñado de manera lógica, coherente y secuencial; siempre en busca de lograr una cabal comprensión de la complejidad inmersa en su concepción y desarrollo. El texto parte de una sólida fundamentación teórica para terminar formulando las recomendaciones más prácticas posibles.

En la figura 1 puede verse el etnomarketing en toda su extensión. Se parte de la cultura como la base de todo el accionar humano. Sobre ella se plantean los postulados del etnomarketing que a su vez sirven de sustento de sus principios esenciales. Desde ellos se trazan los lineamientos teóricos y prácticos para la realización de la antropología de mercados como punta de lanza para la aplicación de las tres funciones básicas del etnomarketing a través de las 15 actividades propuestas. De esta manera, se estudia, analiza e interpreta el comportamiento de los diferentes agentes que participan en los múltiples intercambios que a diario se concretan en cada mercado: de la demanda, de la oferta, de la intermediación y de la regulación.

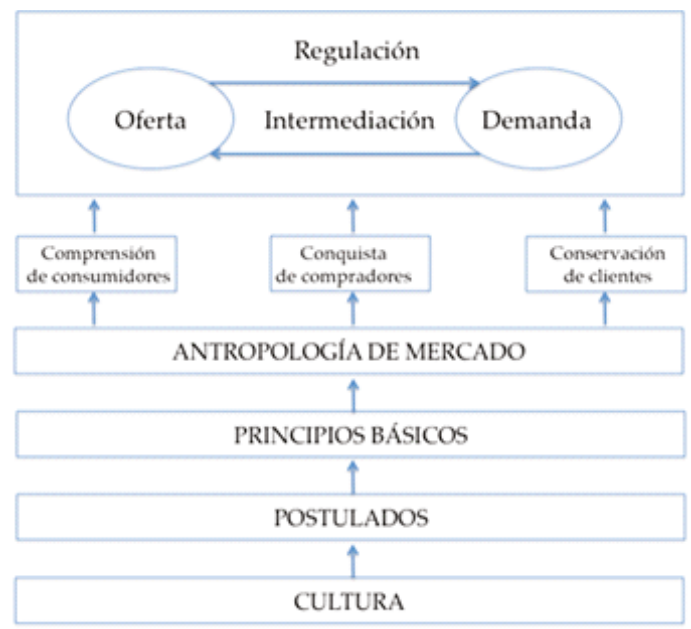

Figura 1. Esquema general del Etnomarketing

La novedad del etnomarketing también se encuentra en la estructuración didáctica y pedagógica de cada capítulo con la que se busca alcanzar una plena comprensión de su contenido. Cada uno de ellos está compuesto de 6 elementos que vistos de manera integral permiten no solo dimensionar su propia complejidad, sino que sirven de guía pragmática para su aplicación en diversas situaciones de mercado:

1) Situación de etnomercado: Recurriendo a técnicas literarias se presenta una situación real de mercado que reclama una solución directa o indirecta que debiera ser ofrecida por una organización. Se hace énfasis en los temas que a través de los diversos personajes y las diferentes situaciones se señalan como esenciales. Se recurre a un lenguaje ameno y sugerente que atraiga la atención de cada lector.

2) Reflexión inicial sobre la situación de etnomercado: Antes de presentar el contenido de cada capítulo, se hace una reflexión que aborda no solo algunas aproximaciones teóricas básicas, sino que intenta orientar la forma en la que podría hacer la lectura del capítulo para ser resolver el problema planteado.

3) Desarrollo teórico: Utilizando un lenguaje fácil -incluso coloquial- se formulan los planteamientos teóricos con toda su rigurosidad académica y científica. Se ha procurado evitar el uso de tecnicismos que obstaculizan una clara y precisa comprensión de los planteamientos formulados. Se busca que no haya trabas -o al menos reducirlas- para su estudio y profundización.

4) Recuadros de etnomarketing: Utilizando una serie de pequeños recuadros denominados "Etnomarketing...", se destacan aquellos elementos que son más relevantes tanto para la comprensión de cada tema abordado, como para la solución de la situación de etnomercado contada al inicio de cada capítulo.

5) Reflexión final sobre etnomercado: Habiendo revisado todo el planteamiento teórico y práctico de cada capítulo, se hace una reflexión final que busca precisar aquellos aspectos de mayor relevancia tanto de cada capítulo como en función de la situación de etnomercado descrita al inicio,

6) Retos y Debates (REDES): Como guía de discusión y de realce de los aspectos más importantes de cada capítulo, se plantea al final de cada uno de ellos una serie de preguntas, ensayos a realizar, frases a analizar, y discusiones a fundamentar. La idea básica no es la de repetir los contenidos desarrollados, por el contrario, se 
busca la argumentación y el debate sobre temas que por lo polémicos deben ser abordados con claridad y contundencia, sin ambigüedades, pero con razones, con convicción y disenso pero sin dogmáticos absolutismos. Se quiere simplemente abrir el debate que contribuya a profundizar cada uno de los planteamientos formulados y con ello dejar los temas abiertos para el disenso y el desacuerdo, o para su ratificación con más y mejor evidencia teórica o práctica.

Etnomarketing, la dimensión cultural del marketing, es el libro que espera romper con la inercia de muchas publicaciones que se han dedicado a copiar formas y modelos extranjerizantes sin ni siquiera consultar la realidad de cada mercado. Su objetivo es muy claro: descubrir, analizar e interpretar cada realidad social y de mercado para que, a partir de ahí, se propongan e implementen las estrategias que basadas en la comprensión de los consumidores, se conciban y se ejecuten ya sea para conquistar los compradores o para conservar a los clientes.

Ojalá que los lectores disfruten este libro tanto como sus autores lo hicieron al escribirlo, pero sobre todo que la mayoría pueda sacarle el mayor provecho posible con la seguridad que si lo hacen como aquí se plantea, los beneficios se sentirán en el logro de los objetivos organizacionales de cada empresa. 